\title{
Erratum to: MBS Measurement Tool for Swallow Impairment-MBSImp: Establishing a Standard
}

\author{
Bonnie Martin-Harris • Martin B. Brodsky • \\ Yvonne Michel - Donald O. Castell • Melanie Schleicher • \\ John Sandidge $\cdot$ Rebekah Maxwell $\cdot$ Julie Blair
}

Published online: 10 February 2010

(C) Springer Science+Business Media, LLC 2010

\section{Erratum to: Dysphagia (2008) 23: 392-405 \\ DOI 10.1007/s00455-008-9185-9}

There was a typographical error in the Table 2: Penetration-aspiration scale. The corrected table follows:

Table 2 Penetration-aspiration scale

\begin{tabular}{llll}
\hline Function & Category & Score & Description \\
\hline Normal & 1 & Material does not enter airway \\
Disordered & 2 & Material enters the airway, remains above the vocal folds, no residue \\
& 3 & Material remains above vocal folds, visible residue remains \\
& 4 & Material contacts vocal folds, no residue \\
& 5 & Material contacts vocal folds, visible residue remains \\
& 6 & Material passes the vocal folds, no subglottic residue visible \\
& 7 & Material passes the vocal folds, visible residue remains despite patient's response \\
& 8 & Material passes the vocal folds, visible residue remains, no patient response \\
\hline
\end{tabular}

The online version of the original article can be found under doi:10.1007/s00455-008-9185-9.

B. Martin-Harris $(\bowtie) \cdot$ M. B. Brodsky

Department of Otolaryngology-Head and Neck Surgery, Medical University of South Carolina, 135 Rutledge Avenue, MSC 550, Charleston, SC 29425-5500, USA

e-mail: harrisbm@musc.edu

B. Martin-Harris · M. B. Brodsky · R. Maxwell · J. Blair Evelyn Trammell Institute for Voice and Swallowing,

Medical University of South Carolina, Charleston, SC, USA

B. Martin-Harris · M. B. Brodsky · R. Maxwell · J. Blair Department of Communication Sciences \& Disorders, Medical University of South Carolina, Charleston, SC, USA

B. Martin-Harris · M. Schleicher · J. Sandidge Evelyn Trammell Voice \& Swallowing Center, Saint Joseph's Hospital of Atlanta, Atlanta, GA, USA
M. B. Brodsky · R. Maxwell · J. Blair

Department of Speech Pathology,

Medical University of South Carolina, Charleston, SC, USA

Y. Michel

College of Nursing, Medical University of South Carolina,

Charleston, SC, USA

D. O. Castell

College of Medicine, Medical University of South Carolina, Charleston, SC, USA

Present Address:

M. B. Brodsky

Johns Hopkins Hospital, Baltimore, MD, USA 